\title{
Purwarupa Sistem Kendali Kestabilan Pesawat Tanpa Awak Sayap Tetap Menggunakan Robust PID
}

\author{
Dwitiya Bagus Widyantara $^{* 1}$, Raden Sumiharto ${ }^{2}$, Setyawan Bekti Wibowo ${ }^{3}$ \\ ${ }^{1}$ Prodi Elektronika dan Instrumentasi, Jurusan Ilmu Komputer dan Elektronika, FMIPA UGM \\ ${ }^{2}$ Jurusan Ilmu Komputer dan Elektronika, FMIPA UGM, Yogyakarta \\ ${ }^{3}$ Program Diploma Teknik Mesin, Sekolah Vokasi UGM \\ e-mail: *1bagusdbw@gmail.com $, \underline{{ }^{2} \text { _sumiharto@ ugm.ac.id, }}, \underline{{ }^{3} \text { setyawanbw @ yahoo.com }}$
}

\begin{abstract}
Abstrak
Pada penelitian ini telah diimplementasikan sebuah sistem kendali kestabilan pesawat tanpa awak sayap tetap (UAV) menggunakan robust PID. Kestabilan pesawat ini mengacu pada pergerakan lurus dalam keadaan gliding yang mampu mempertahankan nilai set poin terhadap gangguan penerbangan berupa angin. Sistem kendali PID pada pesawat mengendalikan sistem gerak aileron, elevator dan rudder. Parameter kendali didapatkan dari sensor IMU berupa data roll, pitch dan yaw. Data tersebut merupakan hasil pengolahan menggunakan algoritma DCM yang menghasilkan euler angles. Tipe kendali PID ditentukan dengan menggunakan teori Ziegler-Nichols metode osilasi.

Teori Ziegler-Nichols metode osilasi menghasilkan tiga jenis sistem kendali yaitu P, PI, dan PID. Hasil yang diperoleh adalah penerapan tipe kendali PID terbaik dengan nilai konstanta $D=0$ untuk masing-masing sistem gerak pesawatnya. Nilai konstanta PID yang digunakan untuk aileron $K p=2.93, K i=2.808$ dan $K d=0$, elevator $K p=2.02, K i=1.731$ dan $K d=0$ dan rudder $K p=1.35, K i=0.9 d a n K d=0$. Pengujian robust menggunakan metode ISE (Integral Squared Error) yang menggantikan integral error pada kendali PID. Sistem diuji menggunakan 2 mode pengujian yaitu mode A (Manual-PID-RobustPID) dan mode B (ManualRobustPID-PID). Hasil yang didapat adalah sistem robust PID mampu membuat respon ketahanan sistem terhadap gangguan menjadi lebih baik daripada PID biasa dengan peningkatan settling time pada aileron $63.67 \%$, elevator $41.42 \%$ dan pada rudder $57.33 \%$.
\end{abstract}

Kata kunci-PID, Pesawat Tanpa Awak, Robust PID

This study has implemented stability control system of Unmanned Aerial Vehicle (UAV) using robust PID. The aircraft stability refers to wind against in glidding condition with straight movement. Robust PID used to control aircraft motion system. Control parameters obtained from the IMU sensor roll, pitch and yaw. IMU data are computed using DCM algorithm that produces Eulerian angles. Type PID control is determined by Ziegler-Nichols methods theory of oscillations. Control system are varied three types, there are P, PI, and PID.

The results have the best type of PID control with $D$ constant value $=0$ for each motion systems. PID constant value used for the aileron $K p=2,93, K i=2,808$ and $K d=0$, elevators $K p=2,02, K i=1,731$ and $K d=0$ and rudder $K p=1,35, K i=0,9$ and $K d=0$. Robust method using ISE (Integral Squared Error) which replaces integral PID control error. The system was tested using two mode. Mode A (Manual-PID-RobustPID) and mode B (Manual-RobustPID$P I D)$. The result of robust PID methods is able to make the system response to disturbances better than regular PID that increase the settling time of aileron $63.67 \%$, elevator $41.42 \%$ and rudder $57.33 \%$.

Keywords-PID, UAV, Robust PID 


\section{PENDAHULUAN}

$\mathrm{P}$ enerapan teknologi kedirgantaraan yang paling banyak dikembangkan dalam beberapa dekade terakhir ini adalah sistem pesawat udara tanpa awak atau disebut juga Unmanned Aerial Vehicle (UAV). Penggunaan pesawat tanpa awak ini sudah banyak digunakan sebagai misi terbang sipil maupun militer. Pada penggunaan misi sipil, pesawat tanpa awak digunakan untuk melakukan pemantauan suatu daerah bencana, pemetaan suatu wilayah dan pengambilan video untuk digunakan dokumentasi film. Pada penggunaan milter, pesawat tanpa awak digunakan untuk misi penyerangan maupun pertahanan suatu Negara. Pengendalian pada UAV memiliki 2 jenis, yaitu manual pilot dan autopilot. Kendali manual pilot pada UAV memiliki cara kerja dimana pesawat menjalankan misi terbang dengan bantuan kendali orientasi pergerakan pesawat oleh operator di darat menggunakan komunikasi jarak jauh. Kendali autopilot pada UAV memiliki cara kerja dimana pesawat dapat terbang dengan kendali yang full autonomous dari kendali gerak orientasi hingga gaya gerak pesawat itu sendiri, hal itu di karenakan adanya penambahan komponen Global Positioning System (GPS) yang diolah oleh prosesor pada pesawat untuk menjalankan misi terbang autopilot.

Untuk dapat mencapai misi terbang sesuai yang diharapkan digunakanlah sebuah sistem kendali terbang (Flight Controller) pada pesawat tanpa awak yang terdiri dari sensor dan pengolah data sensor. Fligh Controller digunakan untuk mengatur kestabilan pesawat saat di udara agar bergerak sesuai yang diinginkan. Perancangan dan implementasi kontroler PID untuk pengaturan heading dan pengaturan arah pada fixed-wing Unmanned Aerial Vehicle (UAV) telah mampu mempertahankan arah pesawat menuju waypoint namun belum optimal mempertahankan posisi terhadap gangguan penerbangan seperti angin pada lintasan yang ditentukan [1]. Mengacu pada penelitian Adi [2]yang menghasilkan sebuah sistem kendali gaya gerak pesawat agar dapat stabil dari nilai set poin pada kondisi trim yang merupakan kondisi dimana pesawat terbang secara lurus ke depan dengan kondisi sayap kanan-kiri sama secara horizontal dan level. Sehingga, dalam penelitian ini akan dibuat sebuah Flight Controller dengan menerapkan metode Robust PID yang mengendalikan dasar sistem gerak pesawat sehingga mampu membuat misi terbang lurus UAV dapat terbang stabil dan optimal.

\section{METODE PENELITIAN}

\subsection{Tinjauan Pustaka}

Kata "Robust" memiliki arti kokoh atau jika dikaitkan dengan sistem, maka sistem dikatakan robust jika pada saat sifat tersebut berada pada satu titik, maka sifat tersebut akan mempunyai kemampuan bertahan terhadap keadaan sekitarnya sehingga mempunyai daya tahan. Suatu sistem pengendali dikatakan robust jika mempunyai sensitifitas rendah, dalam hal ini sistem tidak mudah mengalami suatu perubahan atau osilasi jika diberi suatu gangguan. Sistem akan tetap bisa mempertahankan performansinya.Sistem yang robust akan bisa mempertahankan kestabilan bila diberikan pada variasi parameter tertentu, misalnya pemberian inputan yang berbeda pada sistem yang diharapkan sistem mengalami suatu perubahan proses menjadi proses baru dan sistem masih dalam range kestabilan. Pengendali akan tetap menjaga kesetabilannya dan dapat memperkecil indeks performansi [3].

Teori kendali robust menggunakan asumsi bahwa model yang digunakan dalam merancang sistem kontrol memiliki kesalahan pemodelan. Pada dasarnya, teori berasumsi bahwa ada ketidakpastian atau kesalahan antara sistem aktual dan model matematika, termasuk ketidakpastian tersebut atau kesalahan dalam proses desain sistem kontrol. Sistem dirancang berdasarkan teori kontrol yang kuat akan memiliki sifat atabilitas yang kuat yaitu sistem kontrol yang dirancang stabil dengan adanya gangguan dan memiliki kinerja kuat dengan bukti sistem kontrol yang telah ditentukan karakteristik respon dengan adanya gangguan.

IJEIS Vol. 6, No. 2, October 2016 : $141-150$ 
Integral error secara umum diterima sebagai ukuran yang baik untuk kinerja sistem [4]. Berikut ini adalah beberapa kriteria yang umum digunakan berdasarkan pada integral error untuk setpoin atau respon gangguan :

$$
\begin{aligned}
& \mathrm{IAE}=\int_{0}^{\sim}|e(t)| d t \\
& \mathrm{ISE}=\int_{0}^{\sim} e(t)^{2} d t \\
& \mathrm{ITAE}=\int_{0}^{\sim} t|e(t)| d t \\
& \mathrm{ITSE}=\int_{0}^{\sim} t \mathrm{e}(\mathrm{t})^{2} d t \\
& \mathrm{ISTE}=\int_{0}^{\sim} t^{2} e(t)^{2} d t
\end{aligned}
$$

\subsection{Analisa Kebutuhan Sistem}

Sistem yang dibuat dalam penelitian ini adalah berupa perangkat mikrokontroler Arduino Due, sensor IMU GY-88, Data Logger, pengendali jarak jauh dan sistem gerak pesawat seperti pada Gambar 1. Mikrokontroler arduino Due digunakan sebagai prosesor utama atau pengolah data dalam penerapan sistem kendali maupun pembacaan sensor. Modul sensor IMU GY-88 10-DOF digunakan untuk membaca parameter gaya gerak pesawat, data pembacaan dikirim ke mikrokontroller untuk diolah menjadi sistem kendali pada pesawat menggunakan metode Robust PID Integral Squared Error.

Hasil pengolahan data parameter sensor akan di outputkan pada aktuator servo untuk mengendalikan gaya gerak pesawat untuk menyesuaikan diri sesuai set poin dari gangguan yang diterima sistem. Proses pembacaan sensor dilakukan menggunakan komunikasi $\mathrm{I}^{2} \mathrm{C}$ antara Mikrokontroler dengan GY-88. Setelah itu data sensor diolah secara DCM (Direct Cosine Matrix) agar sensor gerak 9-DOF menjadi output sudut euler dan data tersebut digunakan untuk parameter kendali Robust PID. Sistem gerak pesawat yang digunakan dalam penelitian ini terdiri dari ailleron, elevator, rudder dan motor penggerak pesawat. Untuk menggerakkan ailleron, elevator dan rudder digunakan motor servo sebanyak 4 buah, masing - masing servo dipasang sebanyak 2 buah untuk kendali aileron, 1 buah untuk kendali elevator dan 1 buah untuk kendali rudder. Untuk menggerakkan pesawat digunakan motor brushless yang dihubungkan dengan ESC (Electronic Speed Controller) terlebih dahulu yang berfungsi mengatur kecepatan. Koneksi pada Arduino Due terdapat pada pin PWM out.

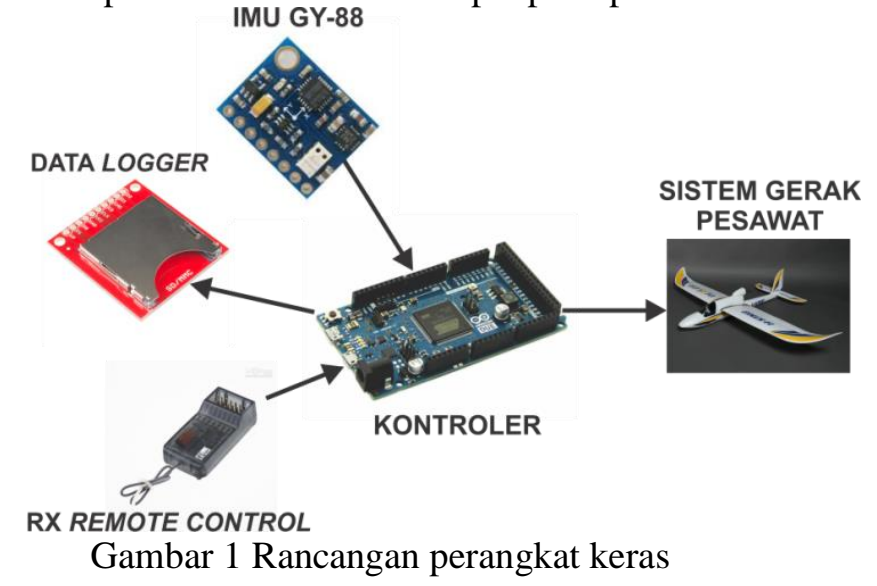

\subsection{Deskripsi Sistem}

Sistem yang akan dibuat dalam penelitian ini adalah sebuah sistem kendali Robust PID yang digunakan untuk mengatur kestabilan pesawat tanpa awak sayap tetap. Sistem kerjanya seperti Gambar 2, dimulai dengan pembacaan pergerakan pesawat dibaca oleh modul sensor IMU GY-88 yang memiliki sensor accelerometer, gyroscope dan magnetometer, lalu data tersebut diolah mengunakan algoritma DCM (Direct Cosine Matrix) untuk diperoleh euler angels dengan output yaw, pitch dan roll. Setelah itu data DCM yang sudah di filter di olah mengunakan teknik Robust PID sebagai nilai parameter sistem kendali. Keluaran pengolahan 
Robust PID digunakan untuk mengatur kestabilan pesawat melalui sistem geraknya yaitu aileron, elevator dan Rudder. Set poin didapat dari pengendali jarak jauh (transmitter) yang diolah oleh prosesor menjadi besaran yang mengatur gerak pesawat. Sensor barometer pada IMU GY-88 dikonversi menjadi ketinggian dimana nilai tersebut akan di linierkan dengan data output kendali dan disimpan dalam data logger sistem untuk dijadikan bahan analisa.

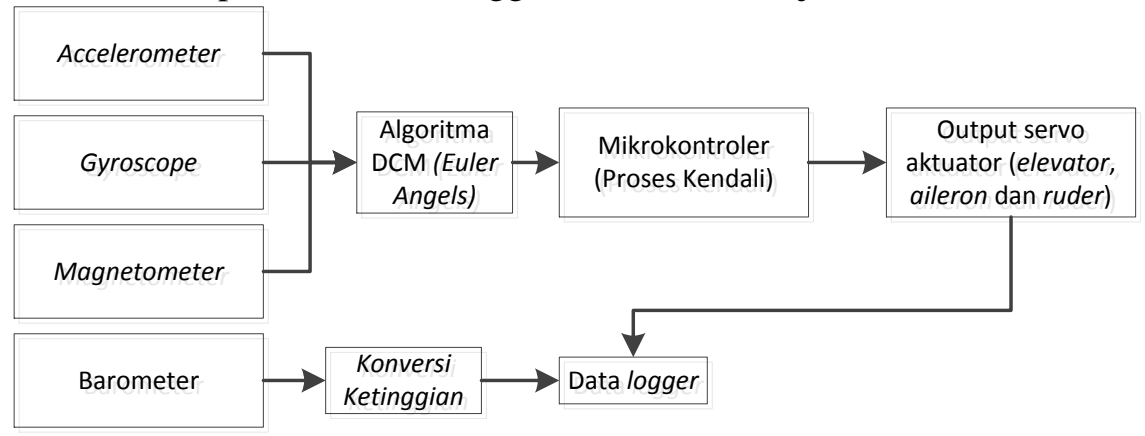

Gambar 2 Arsitektur Sistem

Pada Gambar 3 dijelaskan mekanisme proses kendali yang digunakan dalam sistem ini, setpoin ditetapkan saat kondisi pesawat dalam kondisi setimbang lalu dilakukan akumulasi error untuk dilakukan pengolahan dengan robust PID. Hasil pengolahan robust PID digunakan untuk menggerakkan sistem gerak pesawat yaitu aileron, elevator dan rudder. Sistem gerak pesawat dibaca dengan IMU GY-88 dengan parameter accelerometer, gyroscope dan magnetometer yang diolah menggunakan algoritma DCM untuk diperoleh nilai pergerakan sudut euler. Data pengolahan parameter DCM digunakan untuk akumulasi error dari proses sistem kendali.

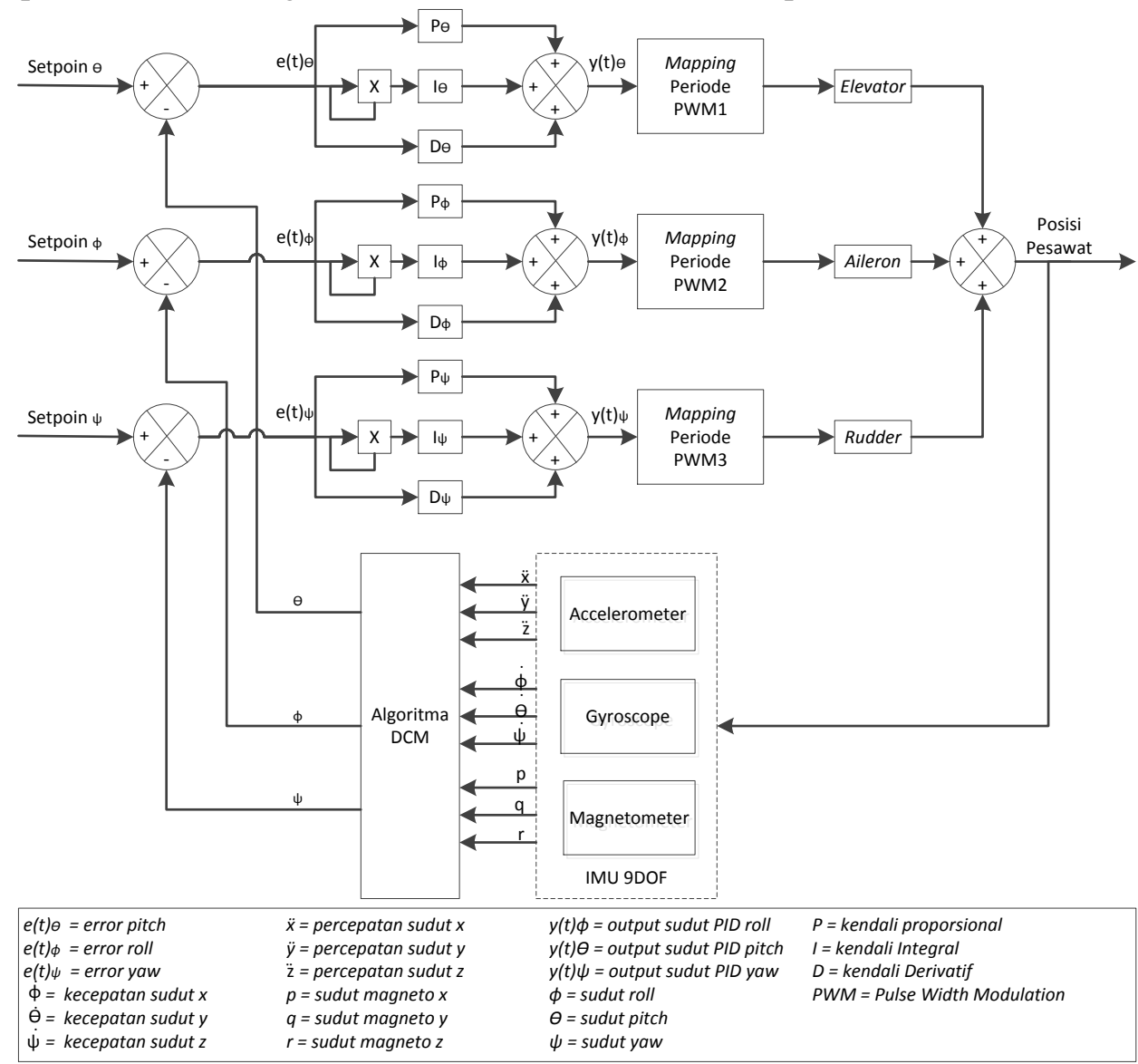

Gambar 3 Diagram blok kendali 


\subsection{Implementasi}

Implementasi perangkat keras terdiri dari Mikrokontroler, IMU GY-88, sistem gerak pesawat dan pengendali jarak jauh (remote control) seperti pada gambar 4. Mikrokontroler arduino due menggunakan shield untuk mempermudah pemasangan sensor IMU dan koneksi dengan pengendali jarak jauh. Pesawat yang digunakan adalah pesawat high wing jenis bixler. Pesawat bixler yang digunakan sudah RTF (Ready To Fly) dimana perangkat keras penggerak seperti motor penggerak pesawat berupa motor brushless, dan motor servo sudah terpasang dengan konfigurasi 2 servo sebagai penggerak aileron dengan menggunakan kabel $\mathrm{Y}(2$ in 1$), 1$ servo sebagai penggerak elevator, dan 1 servo untuk penggerak rudder, untuk bisa terbang pesawat membutuhkan baterai, pengendali jarak jauh dan sistem kendali. Konfigurasi servo dan motor brushless pada arduino due dipasang di pin digital maupun analog yang mampu digunakan sebagai PWM (Pulse With Modulation). Pin 52 digunakan untuk output servo aileron, pin A4 digunakan untuk output elevator, pin A3 digunakan untuk output motor brushless, dan pin A2 digunakan untuk output servo rudder.
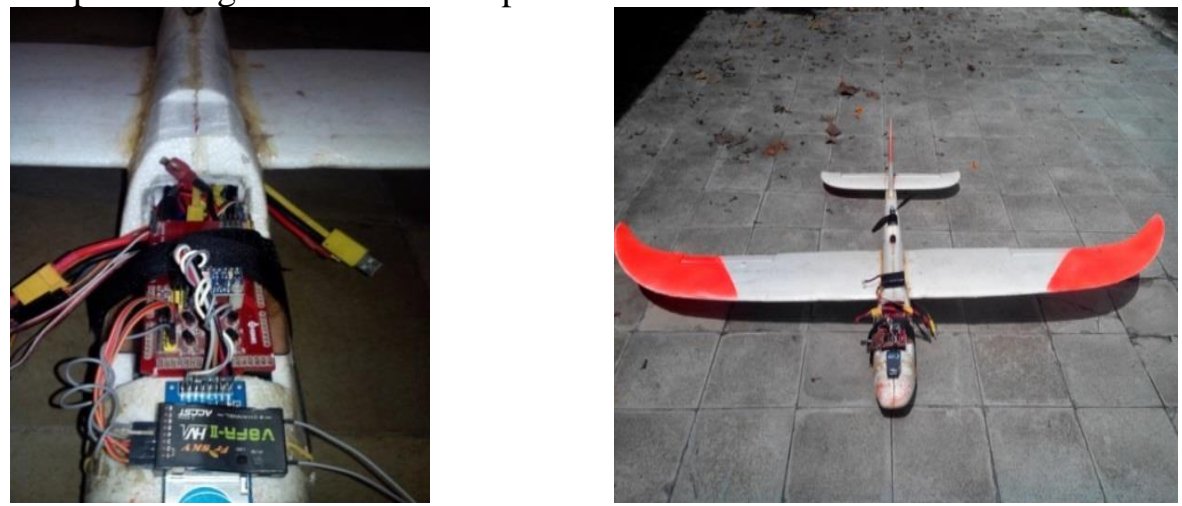

Gambar 4 Implementasi perangkat keras

Untuk implementasi perangkat lunak dimulai dengan pembacaan data dari modul sensor IMU GY-88 yang diolah secara DCM (Direct Cosine Matrix) dan data masukan nilai PWM pengendali jarak jauh. Dalam pembuatan algoritma juga diperlukan pengolahan akses kendali jarak jauh untuk dijadikan parameter mode terbang pesawat yang diinginkan. Data penerbangan hasil kendali di rekam dalam data logger untuk dilakukan analisa.

\section{HASIL DAN PEMBAHASAN}

\subsection{Penentuan Konstanta PID dan Pengujian Tipe Kendali P,PI,PID}

Penentuan konstanta PID dalam sistem ini menggunakan teori Ziegler-Nichols metode osilasi. Metode osilasi ini pertama kali yang ditentukan adalah nilai konstanta ultimate gain $(\mathrm{Ku})$. Osilasi yang dicari adalah osilasi yang stabil sehingga didapatkan konstanta periode osilasi tersebut $(\mathrm{Pu})$. Pengesetan nilai Ku dilakukan dengan memberi nilai Kp tetapi nilai Ki dan $\mathrm{Kd}$ diberi nilai 0 . Setelah dilakukan pengujian $\mathrm{Ku}$ dan $\mathrm{Pu}$ pada masing-masing sistem gerak pesawat didapatkan nilai $\mathrm{Kp}, \mathrm{Ki}$ dan Kd untuk masing-masing sistem gerak pesawat sesuai tabel 1. Setelah ditentukan masing-masing konstanta tipe kendali, maka dilakukan pengujian tipe kendali masing-masing sistem gerak pesawat untuk mendapatkan tipe kendali yang sesuai dengan sistem kestabilan pesawat dalam kondisi glidding dan terbang lurus. 
Tabel 1 Konstanta tipe kendali masing-masing sistem gerak pesawat

\begin{tabular}{|c|c|c|c|c|}
\hline Tipe Kendali & Kp & $\mathbf{K i}$ & Kd & $\begin{array}{c}\text { Sistem } \\
\text { Gerak }\end{array}$ \\
\hline $\mathbf{P}$ & 3.25 & - & - & \multirow{3}{*}{ Aileron } \\
\hline PI & 2.93 & 2.808 & - & \\
\hline PID & 3.9 & 6.24 & 0.6 & \\
\hline $\mathbf{P}$ & 2.25 & - & - & \multirow{3}{*}{ Elevator } \\
\hline PI & 2.02 & 1.731 & - & \\
\hline PID & 2.7 & 3.857 & 0.47 & \\
\hline $\mathbf{P}$ & 1.5 & - & - & \multirow{3}{*}{ Rudder } \\
\hline PI & 1.35 & 0.9 & - & \\
\hline PID & 1.8 & 2 & 0.40 & \\
\hline
\end{tabular}

Berdasarkan pengujian tipe kendali, didapatkan tipe kendali PID dengan nilai $D=0$ untuk masing-masing sistem gerak pesawat. Penambahan komponen kendali derivatif tidak dapat di implementasikan dalam sistem pesawat terbang dalam keadaan glidding dengan kecepatan konstan karena menyebabkan sistem yang sangat reaktif karena pengaruh perubahan parameter yang kecil membuat sistem merespon dengan sangat cepat dan besar sehingga pesawat menjadi kurang mampu menjaga nilai setpoin nya. Karakteristik yang didapatkan dari sistem dengan tipe kendali PID yang nilai $\mathrm{D}=0$ seperti pada Tabel 2.

Tabel 2 Karakteristik hasil pengujian tipe kendali PI

\begin{tabular}{|l|l|}
\hline Sistem Gerak & \multicolumn{1}{c|}{ Hasil pengujian } \\
\hline $\begin{array}{l}\text { Kendali PI } \\
\text { aileron }\end{array}$ & $\begin{array}{l}\text { Rise time: } 0,75 \text { detik } \\
\text { Settling time }: 1.52 \text { detik } \\
\text { Steady state error: } 1.6^{\circ}\end{array}$ \\
\hline $\begin{array}{l}\text { Kendali PI } \\
\text { elevator }\end{array}$ & $\begin{array}{l}\text { Rise time: } 0.9 \text { detik } \\
\text { Settling time }: 1.6 \text { detik } \\
\text { Steady state error: } 2^{\circ}\end{array}$ \\
\hline $\begin{array}{l}\text { Kendali PI } \\
\text { rudder }\end{array}$ & $\begin{array}{l}\text { Rise time: } 0.85 \text { detik } \\
\text { Settling time }: 1.5 \text { detik } \\
\text { Steady state error: } 0,2^{\circ}\end{array}$ \\
\hline
\end{tabular}

\subsection{Penerapan metode Robust PID}

Berdasarkan pengujian tipe kendali P, PI dan PID dengan teori Ziegler - Nichols metode osilasi, didapatkan hasil terbaik dari pengujian tipe kendali tersebut. Hasil terbaik menurut penelitian ini terdapat pada tipe kendali PID dengan $\mathrm{D}=0$. Dengan karakteristik seperti Tabel 1. Sehingga optimasi dalam sistem kendali robust ini dilakukan pada tipe kendali PI dengan mengubah Integral Error (IE) menjadi Integral Squared Error (ISE). Telah diketahui bahwa sistem kendali PID memiliki rumus seperti $u(t)=K_{p} e(t)+K_{I} \int_{0}^{t} e(t) d t+K_{D} \frac{d e(t)}{d t}$ dalam sistem robust ini mengganti $\int_{0}^{t} e(t) d t$ menjadi $\int_{0}^{t} e(t)^{2} d t$ sesuai perumusan ISE.

Rumus ISE dimasukkan ke dalam program mikrokontroler untuk dijadikan mode terbang, sehingga dapat dilakukan pengujian sistem secara keseluruhan dengan membandingkan pola urutan mode terbang. Mode terbang yang digunakan untuk pengujian sistem secara keseluruhan adalah mode A (manual - PI - Robust PI) dan mode B (manual - Robust PI - PI). Setelah mengganti komponen integral error dalam sistem kendali maka dilakukan pengujian sistem seperti saat pengujian sistem untuk tipe kendali P, PI dan PID yaitu dengan memberikan gangguan pada sudut roll melalui pengendali jarak jauh saat mode terbang robust PID. Pengujian mode A dan mode B dilakukan agar mengetahui karakter kestabilan dari perubahan urutan tipe kendali yang dilakukan. 


\subsubsection{Pengujian mode A (manual - PI - robust PI)}

Pengujian ini bertujuan untuk menguji sistem secara keseluruhan dengan membandingkan saat pesawat terbang dalam keadaan tipe kendali manual, PI dan robust PI. PID yang digunakan adalah kendali PID dengan nilai $\mathrm{D}=0$ atau dapat juga disebut kendali PI. Pesawat diterbangkan dengan ketinggian yang berbeda-beda untuk mendapatkan gangguan alami dari lingkungan berupa angin yang datang tidak menentu, selain itu juga diberikan gangguan dari masukan pengendali jarak jauh berupa gerakan roll sebesar $90^{\circ}$ hal ini bertujuan untuk melihat respon kestabilan sistem. Hasil yang di dapat dapat dilihat pada Gambar 5 untuk perbandingan hasil kendali PI dan robust PI.

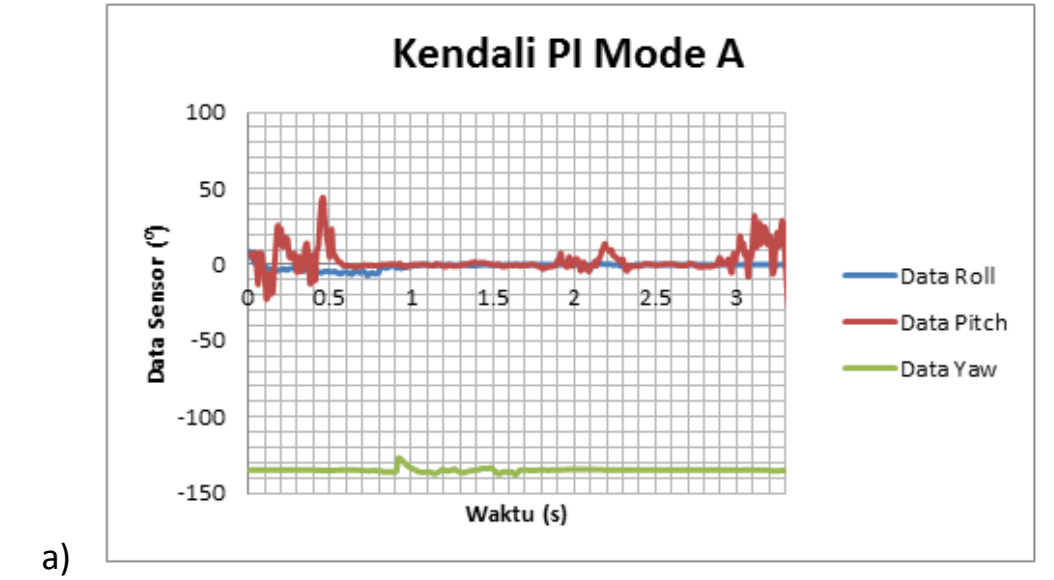

a)

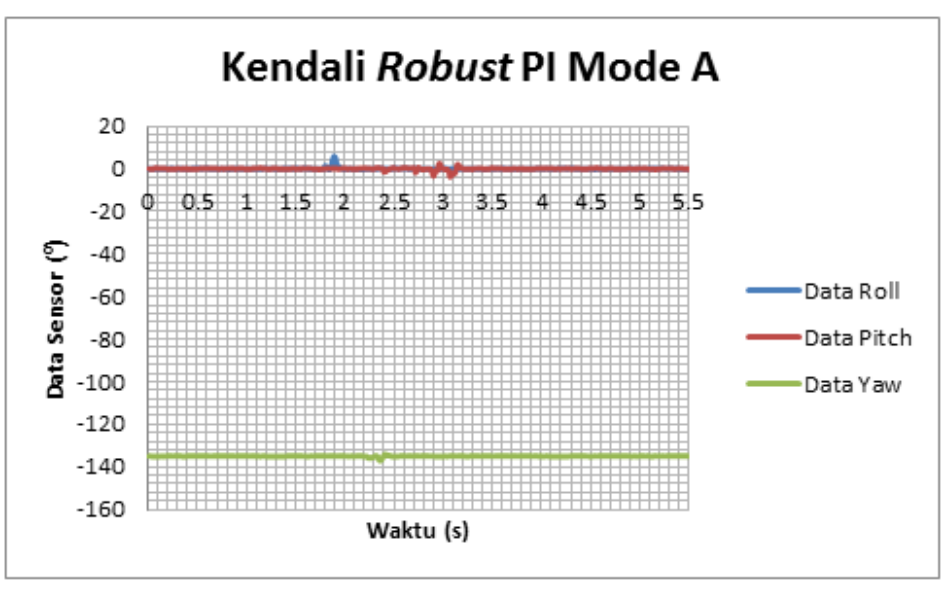

Gambar 5 Perbandingan hasil kendali a) PI dengan b) robust PI mode A

Berdasarkan hasil pengujian sistem kendali robust diketahui sistem mampu menjaga nilai set poin dengan karakteristik seperti Tabel 3. Sistem robust mampu menjaga nilai set poin dengan karakter lebih baik dari kendali PI biasa. Sehingga dapat disimpulkan, penggantian komponen integral error menjadi integral squared error mampu mengoptimasi sistem PI sehingga respon terhadap gangguan menjadi lebih baik dan dapat bertahan dari gangguan di nilai set poin. 
Tabel 3 Karakteristik hasil pengujian tipe kendali PI dan robust PI mode A

\begin{tabular}{|c|l|l|}
\hline \multirow{2}{*}{ Sistem Gerak } & \multicolumn{2}{|c|}{ Hasil pengujian } \\
\cline { 2 - 3 } & \multicolumn{1}{|c|}{ PI } & \multicolumn{1}{|c|}{ Robust PI } \\
\hline Aileron & Rise time: 0,05 detik & Rise time: 0,05 detik \\
& Settling time: 0.35 detik & Settling time: 0.15 detik \\
& Steady state error: $0.4^{\circ}$ & Steady state error: $0.2^{\circ}$ \\
\hline Elevator & Rise time: 0.1 detik & Rise time: 0.09 detik \\
& Settling time: 0.7 detik & Settling time: 0.19 detik \\
& Steady state error: $2^{\circ}$ & Steady state error: $0.4^{\circ}$ \\
\hline Rudder & Rise time: 0.09 detik & Rise time: 0.09 detik \\
& Settling time $: 1.29$ detik & Settling time: 0.59 detik \\
& Steady state error: $0,4^{\circ}$ & Steady state error: $0,2^{\circ}$ \\
\hline
\end{tabular}

\subsubsection{Pengujian mode B (manual - Robust PI -PI)}

Pengujian ini dilakukan untuk melihat respon sistem ketika mode di buat berbeda dari mode A. Pengujuan mode B dilakukan dengan alur kendali manual - robust PI - PI. Pengujian dilakukan dengan ketinggian yang berubah-ubah dilakukan agar sistem mendapat gangguan angin yang datang tidak menentu dan kecepatan angin yang berbeda di setiap ketinggian. Pengujian juga dilakukan dengan memberikan masukan gangguan berupa gerakan roll dari pengendali jarak jauh sebesar $90^{\circ}$ seperti pada mode A agar mengetahui respon sistem ketika diberi gangguan. Hasil yang didapat pada pengujian ini dapat dilihat pada Gambar 6 .

a)
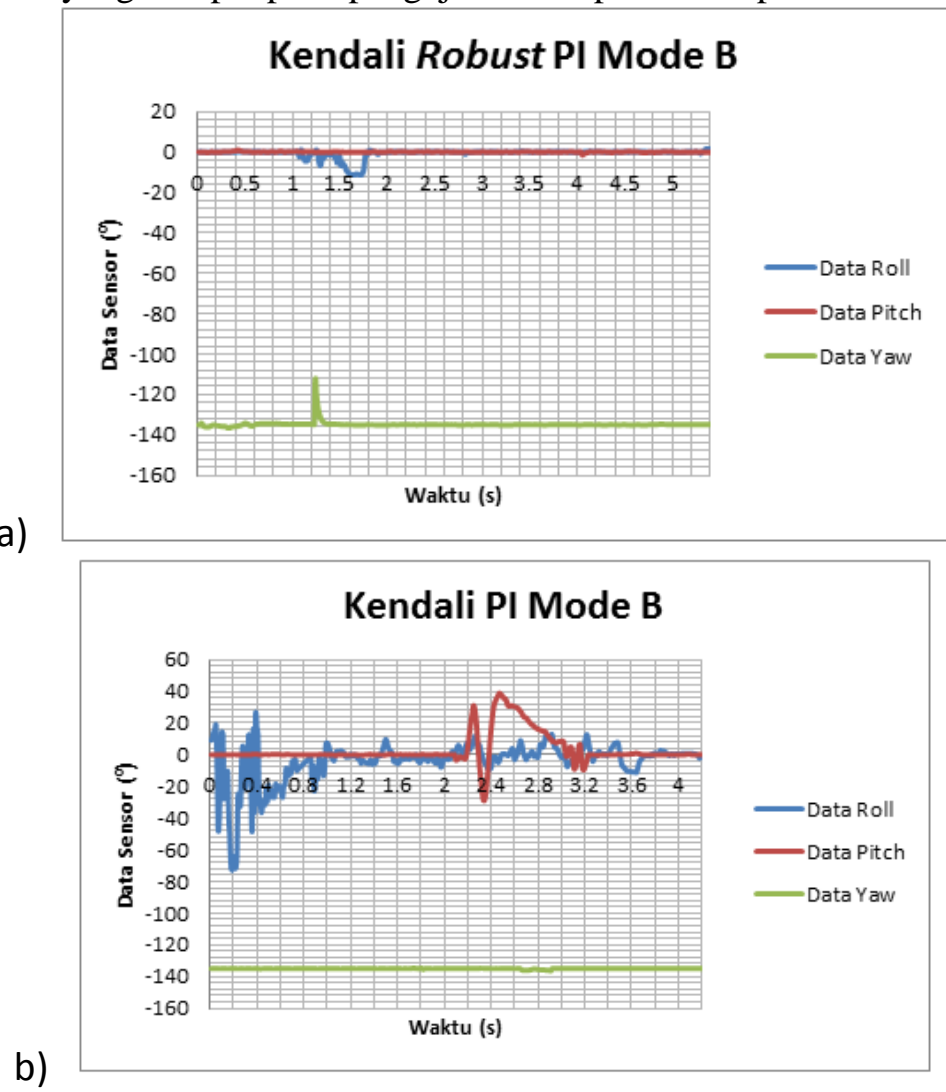

Gambar 6 Perbandingan hasil kendali a) robust PI dengan b) PI mode B 
Dari hasil pengujian sistem kendali dengan alur mode B, didapatkan karakteristik dari tipe kendali PI dan robust PI. Karakteristik robust PI memperbaiki kekurangan dari sistem kendalli PI sehingga sistem mampu menjaga st poin secara optimal serta tahan terhadap gangguan secara alami maupun buatan pada gerak roll. Dengan karakteristik seperti pada Tabel 4.

Tabel 4. Karakteristik hasil pengujian tipe kendali PI dan robust PI mode B

\begin{tabular}{|c|c|c|}
\hline \multirow{2}{*}{ Sistem Gerak } & \multicolumn{2}{|c|}{ Hasil pengujian } \\
\hline & PI & Robust PI \\
\hline Aileron & $\begin{array}{l}\text { Rise time: } 0,36 \text { detik } \\
\text { Settling time: } 1.56 \text { detik } \\
\text { Steady state error: } 0.4^{\circ}\end{array}$ & $\begin{array}{l}\text { Rise time: } 0,27 \text { detik } \\
\text { Settling time: } 0.47 \text { detik } \\
\text { Steady state error: } 0.4^{\circ}\end{array}$ \\
\hline Elevator & $\begin{array}{l}\text { Rise time: } 0.1 \text { detik } \\
\text { Settling time: } 1 \text { detik } \\
\text { Steady state error: } 2^{\circ}\end{array}$ & $\begin{array}{l}\text { Rise time: } 0.1 \text { detik } \\
\text { Settling time: } 0.9 \text { detik } \\
\text { Steady state error: } 0.3^{\circ}\end{array}$ \\
\hline Rudder & $\begin{array}{l}\text { Rise time: } 0.18 \text { detik } \\
\text { Settling time: } 0.48 \text { detik } \\
\text { Steady state error: } 0,1^{\circ}\end{array}$ & $\begin{array}{l}\text { Rise time: } 0.09 \text { detik } \\
\text { Settling time: } 0.19 \text { detik } \\
\text { Steady state error: } 0,01^{\circ}\end{array}$ \\
\hline
\end{tabular}

Berdasarkan pengujian keseluruhan Mode A dan Mode B didapatkan, perbaikan settling time dari kendali metode robust untuk masing-masing sistem gerak pada mode A aileron $0.2 \mathrm{~s}$, elevator $0.51 \mathrm{~s}$ dan rudder $0.7 \mathrm{~s}$, sedangkan pada mode B aileron $1.09 \mathrm{~s}$, elevator $0.1 \mathrm{~s}$ dan rudder $0.29 \mathrm{~s}$. Persentase peningkatan kendali PID menggunakan metode robust ISE didapatkan peningkatan pada mode A sebesar $57.48 \%$ untuk aileron, $72.85 \%$ untuk elevator dan $54.26 \%$ untuk rudder. Sedangkan pada mode B persentase peningkatan PID menggunakan metode robust ISE sebesar $69.87 \%$ untuk aileron, $10 \%$ untuk elevator dan $60.41 \%$ untuk rudder.

\section{KESIMPULAN}

Penelitian sistem kendali kestabilan pesawat tanpa awak sayap tetap menggunakan robust PID menghasilkan kesimpulan sebagai berikut :

1. Tipe kendali PID yang digunakan dari teori Ziegler-Nichols metode kendali osilasi adalah tipe kendali PID dengan nilai $\mathrm{D}=0$.

2. Kendali derivatif tidak dapat ditambahkan dalam kendali kestabilan pesawat, karena pengaruh perubahan parameter yang kecil membuat sistem merespon dengan sangat cepat dan besar sehingga pesawat kurang mampu menjaga nilai set poin nya.

3. Nilai konstanta PID yang digunakan untuk aileron $\mathrm{Kp}=2.93, \mathrm{Ki}=2.808$ dan $\mathrm{Kd}=0$.

4. Nilai konstanta PID yang digunakan untuk elevator $\mathrm{Kp}=2.02, \mathrm{Ki}=1.731$ dan $\mathrm{Kd}=0$.

5. Nilai konstanta PID yang digunakan untuk rudder $\mathrm{Kp}=1.35, \mathrm{Ki}=0.9$ dan $\mathrm{Kd}=0$.

6. Kendali PID dengan metode robust integral squared error menghasilkan sistem kendali yang lebih optimal.

7. Rata-rata persentase peningkatan settling time pada metode robust menggunakan Integral Squared Error pada aileron $63.67 \%$, pada elevator $41.42 \%$ dan pada rudder $57.33 \%$. 


\section{SARAN}

1. Pengendalian ketinggian dapat dilakukan dalam penelitian berikutnya agar pesawat dapat terbang dengan stabil di ketinggiannya.

2. Pengendalian throttle untuk mengatur kecepatan dalam mencapai kondisi kestabilan dapat diterapkan dalam penelitian berikutnya

3. Penggunaan metode kendali robust selain Integral Squared Error (ISE) untuk mendapatkan perbandingan kestabilan dari sistem.

\section{UCAPAN TERIMA KASIH}

Penulis mengucapkan terima kasih kepada PPKI UGM yang telah memberi dukungan finansial terhadap penelitian ini.

\section{DAFTAR PUSTAKA}

[1] Widodo, H.S., K, R.E.A. \& Susila, J., 2012. Perancangan dan Implementasi Kontroler PID untuk Pengaturan Heading dan Pengaturan Arah pada Fixed-Wing Unmanned Aerial Vehicle ( $U A V$ ). Institut Teknologi Sepuluh November. Surabaya.

[2] Adi, Gelang.G., 2014. Purwarupa Sistem Kestabilan Pesawat Tanpa Awak Menggunakan Algoritma Fusion Sensor Kalman Filter Dan Sistem Kendali PID, Skripsi, Jurusan Ilmu Komputer dan Elektronika, Fakultas Matematika dan Ilmu Pengetahuan Alam, Universitas Gadjah Mada, Yogyakarta.

[3] Biyanto, T.R., 2005. Sistem Pengendalian Web Tension Menggunakan Kontroler Robust PID. Jurnal teknik mesin, vol 7, hal 2. Institut Teknologi Sepuluh November. Surabaya.

[4] Tan, W. dkk., 2006. Comparison of some well-known PID tuning formulas, Computers and Chemical Engineering, vol 30, hal.1416-1423. 